\begin{tabular}{|ll|}
\hline \multicolumn{2}{|c|}{ Publisherl nfo } \\
PublisherName & $:$ BioMed Central \\
PublisherLocation & $:$ London \\
Publisherl mprintName & $:$ BioMed Central \\
\hline
\end{tabular}

\title{
Effects of acute systemic dehydration promoted by intravenous furosemide on respiratory mucus in dogs
}

\begin{tabular}{|c|c|c|}
\hline \multicolumn{3}{|c|}{ Articlel nfo } \\
\hline ArticlelD & : 1369 & \\
\hline ArticleDOI & : 10.1186/cc1328 & \\
\hline ArticleCitationID & : P264 & \\
\hline ArticleSequenceNumber & : 257 & \\
\hline ArticleCategory & : Meeting abstract & \\
\hline ArticleFirstPage & $: 1$ & \\
\hline ArticleLastPage & $: 2$ & \\
\hline ArticleHistory & : RegistrationDate & : 2001-1-15 \\
\hline & Received & : 2001-1-15 \\
\hline & OnlineDate & : 2001-3-2 \\
\hline ArticleCopyright & \multicolumn{2}{|c|}{ : Biomed central limited1997 } \\
\hline ArticleGrants & \multicolumn{2}{|l|}{. } \\
\hline ArticleContext & \multicolumn{2}{|l|}{ : 1305455S1S1 } \\
\hline
\end{tabular}

NK Nakagawa, Aff1

F Donato, Aff1

CS Kondo, Aff1

ET Guimarães, Aff1

M King, Aff1

PHN Saldiva, Aff1

G Lorenzi-Filho, ${ }^{\text {Aff1 }}$

Aff1 Experimental Air Pollution Laboratory, Department of Pathology and Department of Cardiopneumology, Universidade de São Paulo, Pulmonary Defense Group, Albertap, Brazil,Canada 


\section{Introduction}

Heat and moisture exchangers (HME) can be used as artificial noses in intubated patients undergoing invasive mechanical ventilation. Intravenous furosemide (F) is widely used in the ICU for volume control. Furosemide could act on respiratory mucus either directly by inhibiting $\mathrm{NaK}(\mathrm{Cl})_{2}$ cotransporter or indirectly by promoting intravascular volume depletion. The aim of this study was to determine the effects of acute systemic dehydration promoted by IV furosemide on respiratory mucus properties, transportability and tracheal transepithelial potential difference in dogs.

\section{Methods}

Thirty six male mongrel dogs, 11 to $15 \mathrm{Kg}$, were anesthetized and submitted to mechanical ventilation for $3 \mathrm{~h}$ with a HME (PALL BB100F). The animals were randomized to control group ( $n=12)$ with no intervention; furosemide group (40mg IV) $(n=12)$ and furosemide + volume replacement group $(n=12)$. Tracheal mucus was collected by suctioning immediately after general anesthesia (Time 0), and after 1 (Time 1) and $2 \mathrm{~h}$ (Time 2) of intervention. Transepithelial potential difference (PD) used as an index of epithelial function was measured at tracheal level. Mucus properties were analyzed by means of 1) in vitro mucus transport by cilia (MCT) on frog palate; 2) cough clearance (CC) by a cough simulator; 3) contact angle (CA) by measuring the angle between a mucus drop and a surface; 4) mucus rheology by a magnetic microrheometer.

\section{Results}

PD decreased in modulus immediately after $\mathrm{F}$ administration, however this effect was partially blunted by fluid replacement. MCT $(P<0.001)$ and CC $(P<0.001)$ increased significantly over time, and CA $(P=$ 0.01 ) and $\log ^{*} 1$ radian/s $(P=0.002)$ decreased in all three groups.

\section{Conclusion}

Our results suggest that physiological compensatory mechanisms of the airways in association with the use of a HME reduce the impact of acute systemic dehydration on mucus physical properties and transportability by cilia and cough.

Supported by FAPESP and Fundação Faculdade de Medicina

\section{References}

1. Trout L, et al.: Am J Physiol 1998, 274: 258-263.

2. Winters SL, Yeates DB: J Appl Physiol 1997, 83: 1360-1369.

3. Basbaum C, et al.: Am Rev Respir Dis 1988, 137: 479-485. 